\title{
Anti-diabetic Activity of Buchanania lanceolata Wight Extracts in Streptozocin persuade Diabetic Animal Model
}

\author{
Saju Thomas ${ }^{1}$, Gunabalan Madhumitha ${ }^{1, *}$ \\ 1 Chemistry of Heterocycles \& Natural Product Research Laboratory, Department of Chemistry, School of Advanced \\ Sciences, Vellore Institute of Technology, Vellore 632014, Tamil Nadu, India \\ * Correspondence: dr.g.madhumitha@gmail.com (G.M.);
}

Scopus Author ID 26429539200

Received: 2.09.2021; Revised: 4.10.2021; Accepted: 8.10.2021; Published: 20.11.2021

\begin{abstract}
Diabetes mellitus is a well-established metabolic syndrome that originates from a complete or virtual requirement of insulin and low insulin action, which leads to hyperglycemia and malformation in the regulation of lipids, proteins, and carbohydrates. Micro and macrovascular difficulties are mainly developed in diabetic patients when compared with normal individuals. The plant variety selected for this study was Buchanania lanceolata Wight (B. lanceolata), which comes under the family of Anacardiaceae, which was originated in India and Myanmar. In the current research, an aqueous extract of $B$. lanceolata was isolated from the plant barks. Glucose uptake was carried out by using L6 myoblast cell lines, and the results showed an improved glucose uptake in vitro by the aqueous extract of bark of B. lanceolata. Moreover, it was also studied for acute dose oral toxicity and anti-diabetic studies in Wistar albino rats. The aqueous extract did not demonstrate any toxic conditions or mortality at single dose feeding of $2000 \mathrm{mg} / \mathrm{kg} / \mathrm{p}$.o and was examined for 15 days. It was also found out the variations in glucose level, hematology parameters, lipid level, and biochemical factors of both control and treated animals. Currently, the natural drug gained attention among researchers because of the problems developed by the allopathic remedial representative. The examination of anti-diabetic agents of an herbal source that are used in folk medicine is thus of huge significance. Management of diabetes with artificial medicines is an expensive and high probability for side effects. As a result, it is necessary to develop plant-based medicines for diabetes. B. lanceolata is a promising herbal drug for diabetic treatment not only in Ayurveda but also in other folk medicine.
\end{abstract}

Keywords: anti diabetic; Buchanania lanceolate; oral toxicity; streptozocin; Wistar albino rats.

(C) 2021 by the authors. This article is an open-access article distributed under the terms and conditions of the Creative Commons Attribution (CC BY) license (https://creativecommons.org/licenses/by/4.0/).

Abbreviations: ATP: adenosine triphosphate; ALP: Alkaline phosphatase; B. lanceolata: Buchanania lanceolata; b.w: Body Weight; DMEM: 'Dulbecco's Modified ' 'Eagle's medium; EDTA: Ethylenediaminetetraacetic acid; FDA: Food and Drug Administration; FBS: Fetal Bovine Serum; GLUT-4: Glucose transporter type 4; HDL: High-Density-Lipoprotein; IAEC: Institutional Animal Ethics Committee; IU: international units; LDL: Low-Density-Lipoprotein; NCCS: National Centre for Cell Science; OECD: Organisation for Economic Co-operation and Development; SGOT: serum glutamic oxaloacetic transaminase; SGPT: serum glutamic-pyruvic transaminase. TNAU: Tamil Nadu Agricultural University.

\section{Introduction}

Nowadays, the most commonly observed pathology is diabetes mellitus, which modifies the body's capability to produce normoglycaemic agents or responds to the hypoglycaemic agent (insulin); thereby, the whole carbohydrate metabolism is damaged. All 
sorts of blood sugar problems cause considerable destruction of $\beta$-cell in the Islets of tissues located in the skin. The immune system in our body falsely attacks our own body pancreatic cells, which leads to a significant breakdown of $\beta$ cells when the patient has type 1 diabetes. Sometimes our body conflicts with normal blood sugar levels because of type 2 diabetics [15]. This persistent syndrome may be alleged or medically recognized by the arrival of signs like excessive urine production, excessive thirst, excessive eating, and uncontrolled weight reduction [6,7]. In addition to chronic hyperglycemia, it can progress to severe hyperglycemia, which can lead to significant problems needing emergency treatment, such as a diabetic coma. Persistent hyperglycemia, even if mild, can develop into issues affecting the eyes, kidneys, nerves, and heart eventually $[8,9]$.

The universal occurrence of blood sugar amongst people above 18 years of age has increased gradually from 4.7 to $8.5 \%$ from 1980 to 2014 . The approximate occurrence of blood sugar for bulge for the year 2035 is 592 million [10]. Normal components have forever been an attractive form for detecting remedies, and various natural medicines have been developed to care for diabetes, ethnopharmacological use; additionally, around 1200 kinds of herbs have been monitored for anti-diabetic action [11-13]. Herbal medicines were frequently utilized because of their large availability, low cost, and reduced side effects.

The final goal of selecting natural remedies for their action is to discover the medicine with strong clinical action and get free from the annoying property like acidity, uncomforting taste, and allergy and kidney problems formed by artificial medicines $[14,15]$.

The plant verify selected for this study was Buchanania lanceolata Wight ( $B$. lanceolata), which comes under the family of Anacardiaceae, an understory plant. The tree is originated in India and Myanmar. It is medically and therapeutically important in the field of Indian traditional medicine. It is an important anti-inflammatory and analgesic activity agent in folk medicine $[16,17]$.

The current work was mainly focused on the result of the water extort of $B$. lanceolata plant on glucose level in the blood, fatty acid profile, the weight of the treated animal, hemoglobin content, glycosylated hemoglobin, biochemical factors, and histopathological screening in streptozocin injected disease model rats [18]. A systematic investigation of the plant revealed that its variants had significant anti-diabetic properties.

\section{Materials and Methods}

\subsection{Collection of plant material and preparation of extract.}

Selected wild plant barks were gathered from the Kasaragod district of Kerala, and the composed variety was recognized by the Botanical Survey of India, Coimbatore (Voucher Specimen no.858). A voucher specimen was set down in the Herbarium of College of Pharmaceutical Sciences, Govt. Medical College Kozhikode, Kerala, India. The dark, dehydrated barks were compacted to crude powder by grinding and were applied to succeeding solvent extraction. The water extracts were concerted by vacuum at room temperature.

\subsection{Identification of phytochemicals.}

Phytochemicals estimation (Table 1) of the whole extort was carried out by the fundamental procedure of Trease and Evans [19]. 
Table 1. Phytochemical analysis results of aqueous extract of B. lanceolata barks.

\begin{tabular}{l|l|l} 
S. No. & Phytochemicals & Observation \\
\hline 1 & Alkaloids & - \\
\hline 2 & Flavanoids & + \\
\hline 3 & Glycosides & - \\
\hline 4 & Tannins & + \\
\hline 5 & Saponin & + \\
\hline 6 & Sterols & + \\
\hline 7 & Carbohydrates & + \\
{$[+]$ presence, $[-]$ Absence } & \multicolumn{1}{l}{}
\end{tabular}

\subsection{In vitro glucose uptake using L6 cell lines.}

The Lee et al. (1987) method followed to determine the amount of glucose uptake on cultured cell lines [20]. The rat myoblast cell line L6 was bought from National Centre for Cell Science (NCCS), Pune, and maintained in Dulbecco's Modified Eagle's medium (DMEM) containing Fetal Bovine Serum (FBS) (10\%) (Invitrogen) and grown in $\mathrm{CO}_{2}(5 \%)$ at $37^{\circ} \mathrm{C}$ in $\mathrm{CO}_{2}$ incubator (NBS, Eppendorf, Germany) to confluence. The cells were then treated with $500 \mu \mathrm{L}$ of trypsin $(0.025 \%)$ and Ethylenediaminetetraacetic acid (EDTA) $(0.5 \mathrm{mM})$ in PBS for $2 \mathrm{~min}$ for the cells to get trypsinized and then transferred to T-flasks in a sterile condition. Sub-culturing of the cells was done in a 24 well plate, and when it attains $80 \%$ confluence, it is placed in DMEM void of glucose for a day.

$1 \mathrm{mg} / \mathrm{mL}$ of stock solution of aqueous extract was prepared simultaneously. The cells grown $(25,50,100,200) \mu \mathrm{g} / \mathrm{mL}$ of the active component were added separately from stock and incubated overnight in DMEM with $300 \mathrm{mM}$ of glucose. The content was spun at 6000 rpm for $10 \mathrm{~min}$, and then cells were isolated. $200 \mu \mathrm{L}$ of lysis buffer with tris-HCl, EDTA, Triton, and $\mathrm{NaCl}$ was added to the pellet and incubated at $4^{\circ} \mathrm{C}$ for $30 \mathrm{~min}$. An untreated control was also maintained with a high glucose level, and the uptake of glucose was determined with a highly sensitive glucose oxidase kit.

\subsection{Animal models.}

Wistar albino is the selected animal model; both male and female were taken with proper Institutional Animal Ethics Committee(IAEC) approval, all are two months old. Each has 200 to $250 \mathrm{~g}$ of body weight, purchased from KLM College of Pharmacy Tamil Nadu, India. Before starting the experiment, 1 day, the animals were fed freshwater only.

\subsection{Single oral toxicity.}

The purpose of this work was to measure the prospective toxicity perspective and to approximate the median lethal dose of water extract of plant's bark when controlled by oral gavage in a solo dose to Wistar rats. Based on Organisation for Economic Co-operation and Development(OECD) guidelines, only the work was done, including the animal handling and chemical tests. As per the organization's rules for economic cooperation and development (2001), the acute toxicity test was performed.

The examination compound was fed as a solo dosage of $1 \mathrm{~mL} / 100 \mathrm{~g}$ body weight(b.wt) for animal models, and the real quantity was intended based on animal models' body weight. The compounds used for the experiment are probable to be harmless, the range of toxicity under the regulatory limit quantity. Following the basic protocol, the initial single dose was 2000 $\mathrm{mg} / \mathrm{kg}$ continued with the same quantity was injected into another four animals [21,22]. 
Observations were made, including changes in different body parts such as body hair, skin color, eyes, etc. Observe their behavioral pattern and give attention to the changes in shaking movements, irregular movement of body parts, salivation, diarrhea, energy rate, sleep, coma, and mortality of the animal models. During the experiment, the weight of each rat was observed, and the variations were calculated. The amount of feed by rats in every group was calculated and recorded from the first day to the last day of the experiment. At last, the animals were sacrificed and taken to histopathology screening.

\subsection{Anti-diabetic study.}

\subsubsection{Initiation of diabetes.}

Blood sugar was injected by intraperitoneal way of $50 \mathrm{mg} / \mathrm{kg}$ body weight of streptozocin, liquefy in newly set citrate buffer. After $72 \mathrm{~h}$, the level of sugar in fasting animals was measured by One Touch Ultra glucometer (Johnson \& Johnson®, Switzerland). The sugar range in blood with fasting is less than $200 \mathrm{mg}$; it can be taken as a diabetic condition [23].

\subsubsection{Assemblage of test animals.}

For this current study, 30 rats were used (24 blood sugar existing rats and 6 ordinary rats); all rats are divided into 5 sections; each section contains 6 rats. The effects of the fraction were evaluated through the oral hypoglycemic compound glyburide [24,25].

Section 1: Control model

Section 2: Disease induced model

Section 3: Disease model induced with drug glyburide $(0.5 \mathrm{mg} / \mathrm{kg}$ for 2 weeks $)$

Section 4: Disease model with plant extract $(200 \mathrm{mg} / \mathrm{kg}$ for 2 weeks)

Section 5: Disease model with plant extract ( $400 \mathrm{mg} / \mathrm{kg}$ for 2 weeks)

\subsubsection{Aqueous extract.}

The fraction of plant material utilized for the current research was suspended each time with water for insertion into the animals.

\subsubsection{Standard drug.}

Glyburide is considered the anti-diabetic medicine with Streptozocin persuaded, and it is helped to assess the anti-diabetic factors of a range of hypoglycaemic particles [26,27]. It was conserved, and the pills were compressed, overhanging in purified water, and utilized throughout the 14 days experiment phase $(0.5 \mathrm{mg} / \mathrm{kg})$. The fed dosage was measured, corresponding to the human remedial dosage, and it was explained by Food and Drug Administration (FDA).

\subsubsection{Oral glucose tolerance evaluation.}

Continually $14 \mathrm{~h}$ all the animals have fasted. The extract was treated for $30 \mathrm{~min}$ and administrated the glucose to each rate with $3 \mathrm{~g} / \mathrm{kg}$ of b.wt. From the tail vein, the blood was collected at each $60 \mathrm{~min}$ interval of D-glucose fed. 


\subsubsection{D-glucose in blood.}

The automated glucometer devises a drop of blood from the rat collected on the test band, which reacted with the blood sample. Following that, the range of D-glucose in the blood was present on the band of the device; the blood was collected between each 60 min with inducing D-glucose. The D-glucose quantity was measured for one week in control and also treated animals for 2 weeks.

\subsubsection{Blood sample collection.}

On the last day of treatment with animals, every rat were sacrificed by applying pressure on the neck and spinal cord, as no fed for the animals during this experimental day. By cardiac puncture, the blood was drawn from the animal. Blood components were disparate by centrifugation and kept for other studies involved in this work.

\subsubsection{Histopathological screening.}

All organs collected from the treated animal were cleaned with saline, and formalin was used to fix a very small division from the organs. The collected tissues were undergone histopathological examination. The examined divisions were fixed on a wax block and placed on a saline-coated glass slide. Then the wax was removed by dewaxing; through this dehydrated, the section with ethanol and stained, and all parts were taken photos $[28,29]$.

\subsubsection{Significance of data.}

Statistical data interpretation was carried out by SPSS 17.0, and the findings were expressed as the mean $\pm \mathrm{SD}$. The statistical comparisons between each section were interpreted by one-way ANOVA. The observations were taken as significantly important if $P$ is $<0.05$.

\section{Results and Discussion}

\subsection{Phytochemical screening.}

\subsubsection{In vitro glucose uptake activity.}

An L6 myoblast cell line is one of the important insulins targeting the tissue that maintains glucose homeostasis. Glucose transporter type-4 (GLUT-4) is one of the main glucose transporter, which is found to be active in adipose tissues and skeletal muscles. Translocation of GLUT-4 is conducted to the cell membrane through the intracellular membrane storing region. GLUT-4 translocation mediates uptake of glucose [30]. This is one of the mediators in the regulation of glucose homeostasis that stimulates glucose through adenosine triphosphate(ATP) independent diffusion to transport glucose across the plasma membrane [31]. The present study explains an improved glucose uptake in vitro by the aqueous extract of bark of B. lanceolata. Glucose uptake has been enhanced by $45.51 \pm 1.08 \%$ than control $(100 \mu \mathrm{g} / \mathrm{mL})$. The anti-diabetic drug Rosiglitazone was used as standard, and the results are compared. It was found that the extract could uptake glucose by $66.08 \pm 1.25 \%$ more than that of the control at $100 \mu \mathrm{g} / \mathrm{mL}$ concentration (Figure 1). 


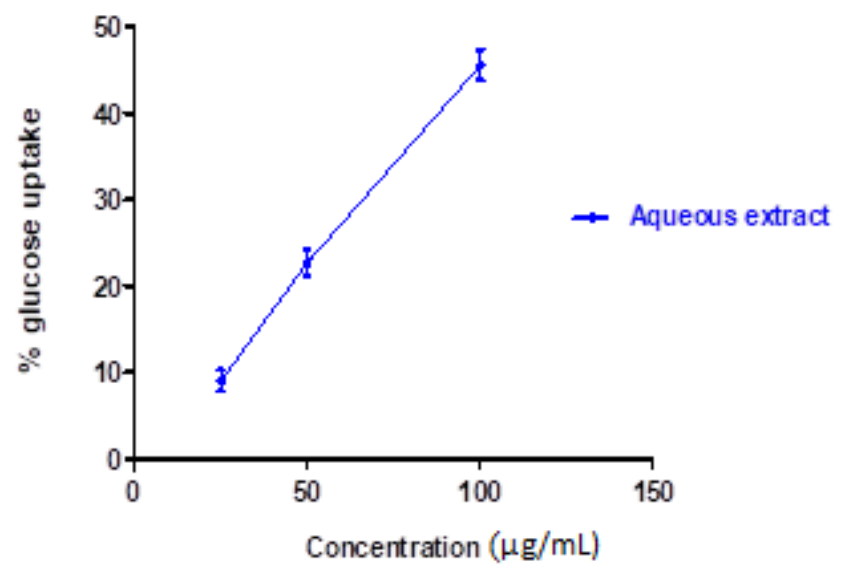

Figure 1. The anti-diabetic activity of the aqueous extract of bark of B. lanceolata.

\subsubsection{Single oral toxicity.}

The present single oral toxicity of plant extracts in animal models, not express any medical symptoms, deaths, and any notable diseases due to toxic effects. The median lethal dose of test components of $B$. lanceolata bark extract when fed single time by orally route in rats $(2000 \mathrm{mg} / \mathrm{kg})$. There was no report on mortality and any other variations in the animals administrated with aqueous plant extract.

\subsubsection{Body weight - animal models.}

The observation of $200 \mathrm{mg} / \mathrm{kg}$ plant extract administration and Streptozocin-induced rats $(400 \mathrm{mg} / \mathrm{kg})$ for two weeks of experiment details are represented in Figure 2. The disease control rats show a loss in between at the second week of treatment. An improvement in body weight showed by plant extract-treated diabetic animals only $(21 \%)$ evaluated with the normal control model but compared with the diabetic control animals, the extract-treated animals show a significant reduction in body weight (26\%).

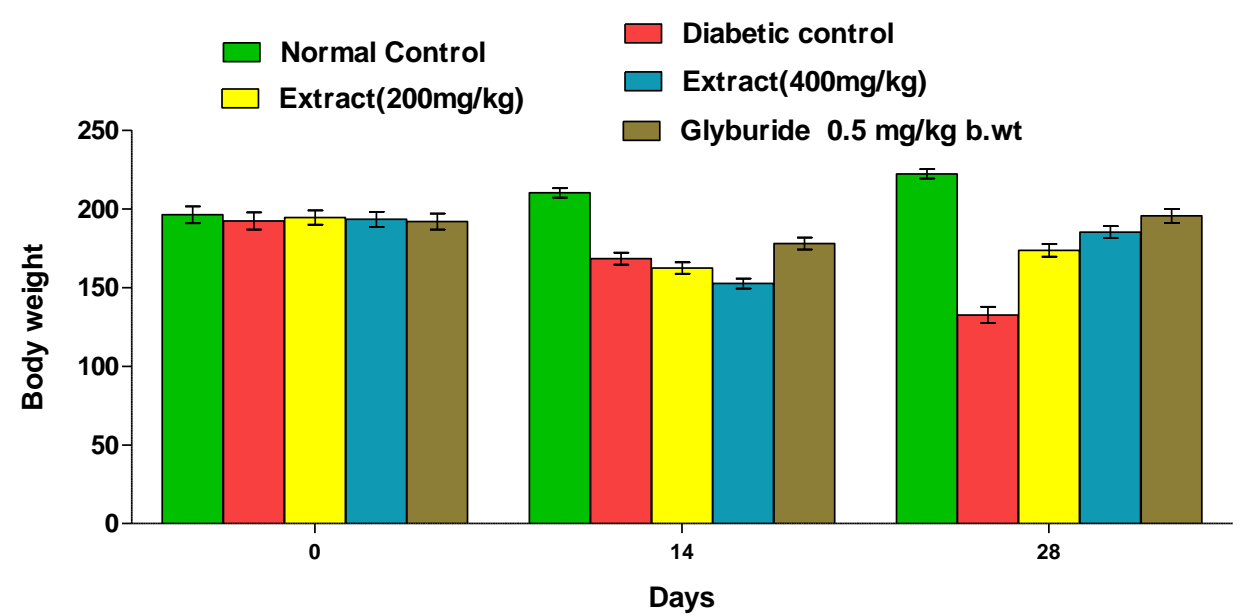

Figure 2. Average body weight with respect to days in the treatment of plant extracts and drug.

\subsection{Anti-diabetic activity.}

\subsubsection{Glucose tolerance test.}

Animals were not fed before the experiment. Group I was taken as control, second group rats only took glucose, the third group of animals received $3 \mathrm{~g}$ of glucose with aqueous 
plant extract $(300 \mathrm{mg} / \mathrm{kg})$ similarly fourth group of rats took $500 \mathrm{mg}$ of plant extract with glucose and group fifth and sixth received only extracts $(300,500) \mathrm{mg} / \mathrm{kg}$. Blood samples were collected at time intervals of $30 \mathrm{~min}$. By using a glucose evaluation kit, the serum glucose level was read out directly. Figure 3 showed a notable change in the D-glucose level of disease model control rats after $60 \mathrm{~min}$ and stays higher over the next $2 \mathrm{~h}$. The plant extract treated animals showed a significant reduction in the level of glucose $(P<0.05)$ at $60 \mathrm{~min}$, and gradually it was reduced by the next $2 \mathrm{~h}$, and it was evaluated with the diabetic control animals.

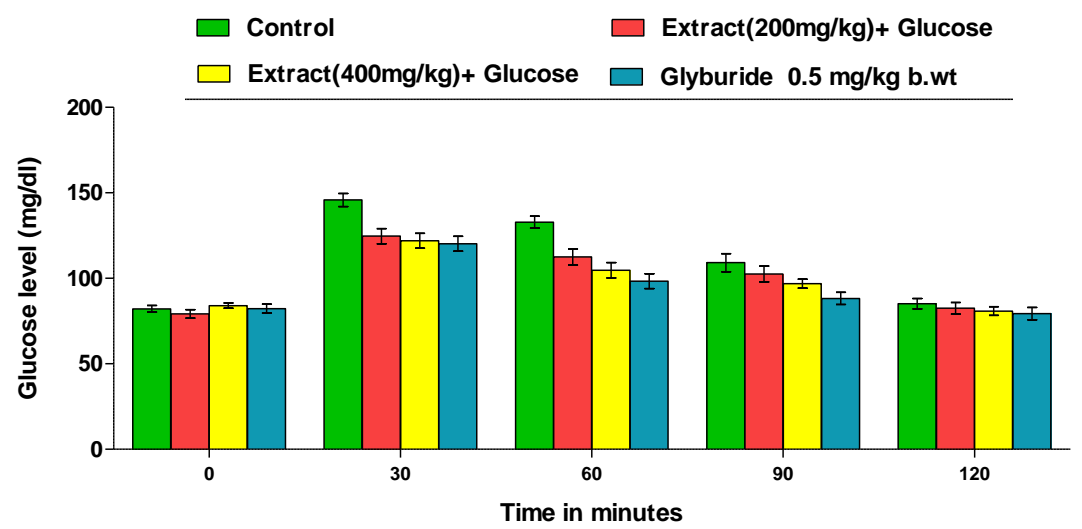

Figure 3. Oral Glucose tolerance test for the aqueous extract of $B$. Lanceolatawith with respect to time.

\subsubsection{D-glucose level.}

The D-glucose quantity in treated animals' blood was estimated at a regular period of days for 2 weeks. Two concentrations of plant extract were fed to the experimental animals, and they expressed great significance in both the concentrations $(200,400) \mathrm{mg} / \mathrm{kg}$, and the findings were demonstrated in Table 2. The end of dosing of D-glucose in Streptozocininduced animals was identified to be considerably prominent when compared with control groups. Oral administration of BAE to the experimental groups showed a significant $(\mathrm{p}<0.01)$ reduction in blood glucose level compared with diabetic control rats. On $14^{\text {th }}$ day of treatment, a maximum reduction of blood glucose level was seen in the disease model with plant extract.

Table 2. Blood glucose level of control and each group of Rattus norvegicus domestica.

\begin{tabular}{|c|c|c|c|c|c|}
\hline \multirow[t]{3}{*}{ Animal groups } & \multicolumn{5}{|c|}{ D-glucose level mg/dl } \\
\hline & \multicolumn{5}{|c|}{ No. of days } \\
\hline & $\mathbf{0}$ & 7 & 14 & 21 & 28 \\
\hline Normal control & $81.2 \pm 2.2$ & $80.6 \pm 1.3$ & $83.8 \pm 1.5$ & $80.1 \pm 1.5$ & $80.6 \pm 1.4$ \\
\hline Diabetic control & $200.3 \pm 3.5$ & $220.4 \pm 6.3$ & $234.8 \pm 2.3$ & $242.6 \pm 5.4$ & $234.2 \pm 4.6$ \\
\hline $\begin{array}{l}\text { Standard control } \\
\text { Glyburide } 0.5 \mathrm{mg} / \mathrm{kg} \text { b.wt }\end{array}$ & $201.8 \pm 2.5$ & $156.3 \pm 2.2$ & $141.5 \pm 2.1$ & $122.6 \pm 1.6$ & $101.4 \pm 2.8$ \\
\hline WEBL $200 \mathrm{mg} / \mathrm{kg}$ & $180.3 \pm 2.6^{*}$ & $170.7 \pm 3.7$ & $146.3 \pm 2.8$ & $140.1 \pm 3.6 * *$ & $126.5 \pm 2.7^{* *}$ \\
\hline WEBL $400 \mathrm{mg} / \mathrm{kg}$ & $180.2 \pm 2.5 *$ & $165.5 \pm 2.4$ & $144.7 \pm 1.7$ & $138.4 \pm 2.3 * *$ & $124.6 \pm 3.9 * *$ \\
\hline
\end{tabular}

All data are expressed as mean \pm standard error mean for all rats in each group. ${ }^{*} \mathrm{p}<0.05,{ }^{*} \mathrm{p}<0.01$ implication between control groups, disease model, and drug-induced animals.

\subsubsection{Fatty acid profile screening.}

The number of fatty acids in various sections of treated rats was monitored, and the observations were expressed in Table 3.

The levels of total cholesterol in the blood of Streptozocin-treated disease model rats were established to be considerably $(\mathrm{p}<0.01)$ prominent when evaluated with control rats. Plant 
extract-treated animal models showed a highly significant $(\mathrm{p}<0.001)$ reduction in total cholesterol range when evaluated with diabetic managed rats (Group II).

Table 3. Fatty acid analysis results of control and each group of Rattus norvegicus domestica.

\begin{tabular}{l|c|c|c|c} 
Treatment groups & $\begin{array}{c}\text { Total } \\
\text { cholesterol IU }\end{array}$ & $\begin{array}{c}\text { Triglycerides } \\
\text { IU }\end{array}$ & $\begin{array}{c}\text { HDL } \\
\text { IU }\end{array}$ & $\begin{array}{c}\text { LDL } \\
\text { IU }\end{array}$ \\
\hline Normal control & $1.2 \pm 0.2$ & $2.3 \pm 0.2$ & $1.5 \pm 0.03$ & $0.9 \pm 0.05$ \\
\hline Diabetic control & $3.7 \pm 0.2$ & $3.8 \pm 0.5$ & $0.7 \pm 0.07$ & $1.06 \pm 0.1$ \\
\hline $\begin{array}{l}\text { Standard control } \\
\text { Glyburide 0.5 mg/kg b.wt }\end{array}$ & $1.6 \pm 0.2$ & $2.5 \pm 0.08$ & $1.4 \pm 0.04$ & $0.8 \pm 0.09$ \\
\hline $\begin{array}{l}\text { Treatment with WEBL } \\
\text { 200mg/kg }\end{array}$ & $1.8 \pm 0.03 * * *$ & $2.3 \pm 0.55^{* * *}$ & $0.6 \pm 0.07$ & $0.9 \pm 0.02 *$ \\
\hline $\begin{array}{l}\text { Treatment with WEBL } \\
400 \mathrm{mg} / \mathrm{kg}\end{array}$ & $1.9 \pm 0.05^{* * *}$ & $2.4 \pm 0.5^{* * *}$ & $0.8 \pm 0.03$ & $0.8 \pm 0.3 * *$ \\
\end{tabular}

The plant extract treated restored the considerable triglycerides $(\mathrm{p}<0.001)$ on disease model rats. In the re-establishment of high-density lipoproteins, more dosages of MEBT $(\mathrm{p}<0.001)$ express large important activity. A small dosage of WEBL $(200 \mathrm{mg} / \mathrm{kg})$ showed a low effect $(\mathrm{p}<0.05)$ and observed a decrease in low-density lipoprotein. Less dosage expresses small significance $(\mathrm{p}<0.01)$, and similarly, high dosage gives large significance $(\mathrm{p}<0.001)$ reduction of LDL in disease model rats.

\subsection{Biochemical analysis.}

\subsubsection{Blood glucose and glycosylated hemoglobin.}

The range of glucose in the blood and glycosylated hemoglobin in control and treated rats were shown in Table 4. The diabetic rats expressed a considerable hike in blood glucose and glycosylated hemoglobin $(\mathrm{p}<0.001)$ when evaluated with standard control rats. The higher and lower doses of MEBT showed a highly major $(\mathrm{p}<0.001)$ reduction in the blood glucose and glycosylated hemoglobin levels in diabetic-treated rats.

Table 4. Hemoglobin and Glycosylated hemoglobin level of control, extract, and drug-treated rats at various ranges.

\begin{tabular}{l|c|c} 
Experimental animal models & Hemoglobin & Glycosylation of hemoglobin \\
\hline Control & $14.3 \pm 0.6$ & $4.3 \pm 0.4$ \\
\hline Disease model & $10.2 \pm 0.4$ & $12.9 \pm 1.7$ \\
\hline $\begin{array}{l}\text { Glyburide } \\
(0.5 \mathrm{mg} / \mathrm{kg})\end{array}$ & $13.6 \pm 1.7$ & $5.3 \pm 1.8$ \\
\hline WEBL $(200 \mathrm{mg} / \mathrm{kg})$ & $11.2 \pm 0.7^{*}$ & $7.6 \pm 1.9^{*}$ \\
\hline WEBL $(400 \mathrm{mg} / \mathrm{kg})$ & $13.7 \pm 1.8^{*}$ & $4.9 \pm 1.6^{* *}$ \\
\hline $\begin{array}{l}\text { All data's shown as mean } \pm \text { standard error means for all rats in all groups. *p<0.05, } \\
* * p<0.01, * * * \mathrm{p}<0.001 \text { significance, among control rats, disease-induced models and drug-induced } \\
\text { animals. }\end{array}$
\end{tabular}

\subsubsection{Enzymes markers - liver.}

Enzyme markers like Serum glutamic oxaloacetic transaminase (SGOT), Alkaline phosphatase (ALP), and Serum glutamic-pyruvic transaminase (SGPT) are the most common liver enzymes, which helps to find out the level of a particular enzyme in the liver. Here Table 5 contains the rate of enzymes in the serum of the diabetic induced animal model.

The results show that the enzyme level augmented extensively $(\mathrm{p}<0.001)$ in diseaseinduced rats when evaluated to standard control rats. Feeding of two dosages of WEBL return 
the Serum glutamic oxaloacetic transaminase extremely considerably $(\mathrm{p}<0.001)$ on diabetic persuade rats.

Table 5. Analysis results of the level of liver enzyme markers of control and treated animal groups.

\begin{tabular}{l|c|c|c|c}
$\begin{array}{c}\text { Experimental } \\
\text { animal models }\end{array}$ & $\begin{array}{c}\text { Glycosylationhae } \\
\text { moglobin }\end{array}$ & $\begin{array}{c}\text { Serum glutamic } \\
\text { oxaloacetic transaminase }\end{array}$ & $\begin{array}{c}\text { Serum glutamic pyruvic } \\
\text { transaminase }\end{array}$ & Alkaline phosphatase \\
\hline Control & $4.3 \pm 0.4$ & $25.2 \pm 2.6$ & $31.8 \pm 1.7$ & $149.9 \pm 4.4$ \\
\hline Disease model & $12.9 \pm 1.6$ & $56.0 \pm 4.8$ & $51.6 \pm 1.9$ & $160.2 \pm 5.4$ \\
\hline WEBL $(200 \mathrm{mg} / \mathrm{kg})$ & $7.5 \pm 1.9^{*}$ & $26.3 \pm 1.4^{* * *}$ & $38.5 \pm 5.6^{* *}$ & $160.6 \pm 5.8^{*}$ \\
\hline WEBL $(400 \mathrm{mg} / \mathrm{kg})$ & $4.8 \pm 1.6^{* *}$ & $23.2 \pm 1.1^{* * *}$ & $32.2 \pm 0.7^{* *}$ & $161.5 \pm 3.7^{*}$ \\
\hline \multicolumn{2}{|r|}{ All data's shown as mean \pm standard error means for all rats in all groups.*p<0.05, **p<0.01,***p<0.001 significance, among control }
\end{tabular}
rats, disease-induced models, and drug-induced animals.

More dose of WEBL $(\mathrm{p}<0.001)$ leads to higher significance $(\mathrm{p}<0.01)$, and less dose shows low significance $(\mathrm{p}<0.05)$ during the re-establishment of Serum Glutamic Pyruvic Transaminase. Maximum dose of WEBL leads to the reduction of ALP in diabetic rats.

\subsubsection{Histopathology screening.}

Figure 4A denotes the standard control groups: Seen normal functional tissue in the organ with extra or fewer regular components in hepatic lobule and vascular channels; figure 4B shows diabetic induced animal models express some enlargement and blockage. From the figure, seen the macrophages along with vascular channels in the liver tissue, and protein synthesis cells in the liver tissue at different stages of deterioration; figure $4 \mathrm{C}$ represents the WEBL treated rats showed white blood cells penetration propagating bile capillaries also seen are macrophages along with vascular channels in the liver tissue; figure 4D specifies the plant extract treated $(200 \mathrm{mg} / \mathrm{kg})$ diabetic animal models; the picture showed excess white blood cells penetration in regular components in hepatic lobule and condensing of the blood vessel wall. Macrophages along with vascular channels in the liver tissue were also seen, and figure $4 \mathrm{E}$ signifies the plant extract treated $(400 \mathrm{mg} / \mathrm{kg})$ diabetic animal models; the picture showed excess white blood cells penetration in portal triads. Moreover, the histopathological section of the control rat's pancreas showed usual cells, and in diabetic induced rats showed a sensible enlargement in the tissues. The formation of several vacuoles within the cells was observed and also found a blockage in pancreatic cells. It causes by the reduction in the number of cells and reveals the soft penetration mechanism of inflammatory cells. In the case of WEBL treated animals, the inflammation in the pancreatic cells was recovered, soft the blockage in the tissue, and the cell count was improved. The histopathological image gives a clear idea (Figure 4).

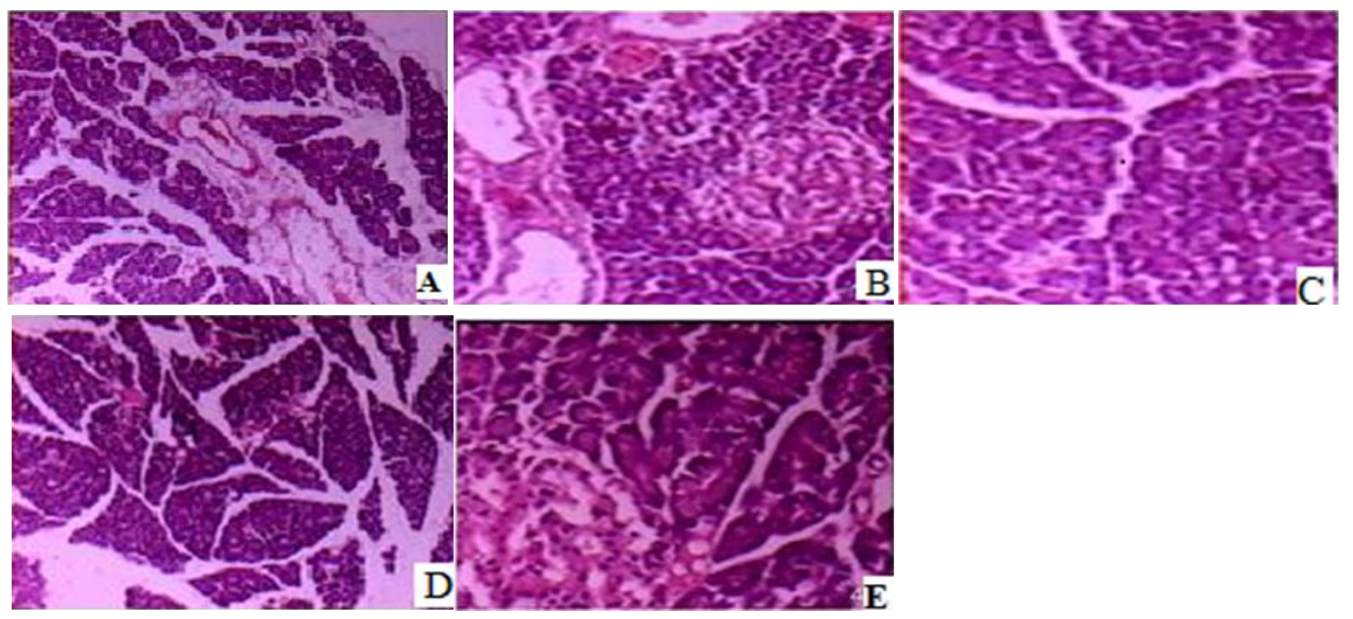

Figure 4. Histopathological sections of liver in plant extract treated rats and control group of rats. 


\subsection{Discussion.}

The present study was accomplished by an aqueous extract of $B$. lanceolata bark which exhibits better anti-diabetic action. Further, phytochemical screening of B. lanceolata showed the presence of flavonoids, phenolics tannin, saponin, sterols, and carbohydrates (Table 1) [10]. Alkaloids and glycosides analysis were found to be negative. The plant extract also exhibited blood sugar as showed by various factors like body weight and fatty acid [32]. The rate of liver enzyme markers was higher in all groups of animals when compared with the control group. Streptozotocin-induced type 1 diabetes disease development in rats is linked to altering the intestinal microbiota composition [33,34]. In this study, the liver injury in WEBL induced disease-treated rats (Figure 4) and renewal of cells by glyburide were also identified. It is established that aqueous bark extract at a large dosage $(400 \mathrm{mg} / \mathrm{kg})$ is highly active than the extract at a small dosage $(200 \mathrm{mg} / \mathrm{kg})$ even after 2 weeks of treatment. Therefore, our study unveils that aqueous barks of plant extract at a higher dose $(400 \mathrm{mg} / \mathrm{kg})$ are more effective and show similar drug action as the standard drug, glyburide. Eventually, histopathological screening exhibits the curative of the liver, by B. lanceolata extracts, as a probable action of anti-diabetic action [35].

\section{Conclusions}

The barks of plant extract did not express a reliable result on the standard range of blood sugar, but it successfully inverted the rug induced variations of the sugar level in blood and the $\beta$ cell development in the liver. It also expressed a defensive action when it was known proceeding to drug feeding [30]. The effect of barks extracts on the $\beta$ cells and lack of toxicity may suggest a novel trust to the people with diabetes in the future.

It can be concluded that aqueous barks extract of $B$. lanceolata at the maximum dose (400) $\mathrm{mg} / \mathrm{kg}$ revealed important anti-diabetic action than plant extract at small dosage (200) $\mathrm{mg} / \mathrm{kg}$ in drug-treated disease model animals. The plant compounds also expressed progress in factors like b.wt and fatty acid screening as well as renewal of cells of liver cells and so power be of worth in disease management. Additional examination is in essential to conclude the correct phytochemicals accountable for anti-diabetic action.

\section{Funding}

This research received no external funding.

\section{Acknowledgments}

We thank VIT management for their support and encouragement.

\section{Conflicts of Interest}

The authors declare no conflict of interest.

\section{References}

1. Cnop, M.; Welsh, N.; Jonas, J-C.; Lenzen, S.; Eizirik, D.L. Mechanisms of pancreatic beta-cell death in type 1 and type 2 diabetes: many differences, few similarities. Diabetes 2005, 54, 97-107, https://doi.org/10.2337/diabetes.54.suppl_2.S97.

2. Padhi, S.; Nayak, A.K.; Behera, A. Type II diabetes mellitus: A review on recent drug based therapeutics. Biomedicine \& Pharmacotherapy 2020, 131, https://doi.org/10.1016/j.biopha.2020.110708. 
3. Luciano-Feijoó, M.; Cabañas, J.G.; Brice, J.H. Diabetic emergencies. Emergency Medical Services: Clinical Practice and Systems Oversight 2021, 1, 188-193, https://doi.org/10.1002/9781119756279.ch20.

4. Jugran, A.K.; Rawat, S.; Devkota, H.P.; Bhatt, I.D.; Rawal, R.S. Diabetes and plant-derived natural products: From ethnopharmacological approaches to their potential for modern drug discovery and development. Phytotherapy Research 2021, 35, 223-245, https://doi.org/10.1002/ptr.6821.

5. Gomes, A.; Coelho, P.; Soares, R.; Costa, R. Human umbilical cord mesenchymal stem cells in type 2 diabetes mellitus: the emerging therapeutic approach. Cell and Tissue Research 2021, 385, 497-518, https://doi.org/10.1007/s00441-021-03461-4.

6. Eliza, J.; Daisy, P.; Ignacimutha, S.; Duraipandiyan, V. Normo-glycemic and hypolipidemic effect of costunolide isolated from Costusspeciosus (Koen ex. Retz.) Sm. in streptozotocin-induced diabetic rats. Chem Biol Ineract 2009, 179, 329-34, https://doi.org/10.1016/j.cbi.2008.10.017.

7. Kroll, C. Questioning Biomedicine's Privileging of Disease and Measurability. AMA Journal of Ethics 2021, 23, 537-541, https://doi.org/10.1001/amajethics.2021.537.

8. Huang, R.; Tian, S.; Zhang, H.; Zhu, W.; Wang, S. Chronic hyperglycemia induces tau hyperphosphorylation by downregulating OGT-involved O-GlcNAcylation in vivo and in vitro. Brain research bulletin 2020, 156, 76-85, https://doi.org/10.1016/j.brainresbull.2020.01.006.

9. Siddiqui, A.A.; Siddiqui, S.A.; Ahmad, S.; Siddiqui, S.; Ahsan, I.; Sahu, K. Diabetes: Mechanism, pathophysiology and management-A review. International Journal of Drug Development and Research 2013, $5,1-23$.

10. Alamin, M.A.; Yagi, A.I.; Yagi, S.M. Evaluation of anti-diabetic activity of plants used in western Sudan. Asian Pac. J. Trop. Biomed. 2015, 5, 395-402, https://doi.org/10.1016/S2221-1691(15)30375-0

11. Andrade, C.; Gomes, N.G.; Duangsrisai, S.; Andrade, P.B.; Pereira, D.M.; Valentao, P. Medicinal plants utilized in Thai Traditional Medicine for diabetes treatment: ethnobotanical surveys, scientific evidence and phytochemicals. Journal of ethnopharmacology 2020, 5, https://doi.org/10.1016/j.jep.2020.113177.

12. Jia, A.; Zhang, Y.; Gao, H.; Zhang, Z.; Zhang, Y.; Wang, Z.; Zhang, J.; Deng, B.; Qiu, Z.; Fu, C. A review of Acanthopanax senticosus (Rupr and Maxim.) Harms: from ethnopharmacological use to modern application. Journal of Ethnopharmacology 2020, 268, https://doi.org/10.1016/j.jep.2020.113586.

13. El-Hilaly, J.; Tahraoui, A.; Israili, Z.; Lyoussi, B. Hypolipidemic effects of acute and sub-chronic administration of an aqueous extract of Ajugaiva L. whole plant in normal and diabetic rats. J. Ethnopharmacol. 2006, 105, 441-448, https://doi.org/10.1016/j.jep.2005.11.023.

14. Phang, M.W.L.; Lew, S.Y.; Chung, I.; Lim, W.K.S.; Lim, L.W.; Wong, K.H. Therapeutic roles of natural remedies in combating hereditary ataxia: A systematic review. Chinese medicine 2021, 16, 1-22, https://doi.org/10.1186/s13020-020-00414-X.

15. Cheng, B.; Fu, X. Problems and Prospects in Regenerative Medicine. In: Regenerative Medicine in China. Fu, X. (eds) Springer, Singapore. 2021; pp. 463-485, https://doi.org/10.1007/978-981-16-1182-7_14.

16. Kumar, E.S.; Shareef, S.M.; Vikraman, R.R. A new variety of Buchanania lanzan (Anacardiaceae) from Kerala, India. I3 Biodiversity 2020, 8, 1-5.

17. Gandhi, G.R.; Sasikumar, P. Antidiabetic effect of Merremiaemarginata (Burm. F.) in streptozotocin induced diabetic rats. Asian Pac. J. Trop. Biomed. 2012, 2, 281-6, https://doi.org/10.1016/S2221-1691(12)60023-9.

18. Sasidharan, N. Biodiversity documentation for Kerala Part 6. Flowering plants. KFRI handbook. 2004 ; pp.7.

19. Manandhar, N.; Bajgain, K.; Neupane, A. Study on Phytochemical Profile and Antioxidant Activity of Achyranthes aspera Whole Plant. Medicine 2021, 3, https://doi.org/10.9734/ijbcrr/2021/v30i230251.

20. Lee, M.D.; Zentella, A.; Vine, W.; Pekala, P.H.; Cerami, A. Effect of endotoxin-induced monokines on glucose metabolism in the muscle cell line L6. Proc. Natl Acad Sci 1987, 84, 2590-4, https://doi.org/10.1073/pnas.84.9.2590.

21. Eidi, A.; Esmaeili, E. Antidiabetic effect of garlic (Allium sativum L.) in normal and streptozotocin-induced diabetic rats. Phytomedicine 2006, 13, 624-9, https://doi.org/10.1016/j.phymed.2005.09.010.

22. Valic, M.S.; Halim, M.; Schimmer, P.; Zheng, G. Guidelines for the experimental design of pharmacokinetic studies with nanomaterials in preclinical animal models. Journal of Controlled Release 2020, 323, 83-101, https://doi.org/10.1016/j.jconrel.2020.04.002.

23. Andrade-Cetto, A.; Martinez-Zurita, E.; Wiedenfeld, H. Chronic hypoglycemic effect of Malmeadepressa root on n5-streptozotocin diabetic rats. J. Ethnopharmacol. 2008, 116, 358-62, https://doi.org/10.1016/j.jep.2007.11.043.

24. Oyedemi, S.O.; Adewusi, E.; Aiyegoro, O.A.; Akinpelu, D.A. Antidiabetic and haematological effect of aqueous extract of stem bark of Afzeliaafricana (Smith) on streptozotocin-induced diabetic Wistar rats. Asian Pac. J. Trop. Biomed. 2011, 1, 353-8, https://doi.org/10.1016/S2221-1691(11)60079-8.

25. Jales, J.T.; de Moura Barbosa, T.; Dos Santos, L.C.; Rachetti, V.D.P.S.; Gama, R.A. Carrion decomposition and assemblage of necrophagous dipterans associated with Terbufos (Organophosphate) intoxicated rat carcasses. Acta tropica 2020, 212, https://doi.org/10.1016/j.actatropica.2020.105652.

26. Ugochukwu, N.H.; Babady, N.E.; Cobourne, M.; Gasset, S.R. The effect of Gongronemalatifolium extracts on serum lipid profile and oxidative stress in hepatocytes of diabetic rats. J. Biosci. 2003, 28, 1-5, https://doi.org/10.1007/BF02970124. 
27. Benítez, V.; Rebollo-Hernanz, M.; Aguilera, Y.; Bejerano, S.; Cañas, S.; Martín-Cabrejas, M.A. Extruded coffee parchment shows enhanced antioxidant, hypoglycaemic, and hypolipidemic properties by releasing phenolic compounds from the fibre matrix. Food \& Function 2021, 12, 1097-1110, https://doi.org/10.1039/D0FO02295K.

28. Siddique, S.; Shoaib, A.; Khan, S.N.; Mohy-Ud-Din, A. Screening and histopathological characterization of sunflower germplasm for resistance to Macrophominaphaseolina. Mycologia 2021, 113, 92-107, https://doi.org/10.1080/00275514.2020.1810516.

29. Duran-Lopez, L.; Dominguez-Morales, J.P.; Rios-Navarro, A.; Gutierrez-Galan, D.; Jimenez-Fernandez, A.; Vicente-Diaz, S.; Linares-Barranco, A. Performance Evaluation of Deep Learning-Based Prostate Cancer Screening Methods in Histopathological Images: Measuring the Impact of the Model's Complexity on Its Processing Speed. Sensors 2014, 21, https://doi.org/10.3390/s21041122.

30. Sujatha, S.; Anand, S.; Sangeetha, K.N.; Shilp, K.; Lakshmi, J.; Balakrishnan, A.; Lakshmi, B.S. Biological evaluation of (3ß)-STIGMAST-5-EN-3-OL as potent anti-diabetic agent in regulating glucose transport using in vitro model. International Journal of Diabetes Mellitus 2010, 2, 101-9, https://doi.org/10.1016/j.ijdm.2009.12.013.

31. Huang, S.; Czech, M.P. The GLUT4 glucose transporter. Cell metab. 2007, 5, 237-52, https://doi.org/10.1016/j.cmet.2007.03.006.

32. Ahmed, M.F.; Kazim, S.M.; Ghori, S.S; Mehjabeen, S.S.; Ahmed, S.R.; Ali, S.M.; Ibrahim, M. Antidiabetic Activity of Vinca rosea extracts in Alloxan-Induced Diabetic Rats. Int J Endocrinol. 2010, 2010, https://doi.org/10.1155/2010/841090.

33. Gorray, K.C.; Baskin, D.; Brodsky, J, Fujimoto, W.Y. Responses of pancreatic B cells to alloxan and streptozotocin in the guinea pig, Pancreas 1986, 1, 130-8, https://doi.org/10.1097/00006676-19860300000004.

34. Rao, R.M.; Salem, F.A.; Gleason-Jordan I. Antidiabetic effects of a dietary supplement "Pancreas Tonic". J. Natl. Med. Assoc. 1998, 90, 614-8.

35. Arora, M.K.; Reddy, K.; Balakumar, P. The low dose combination of fenofibrate and rosiglitazone halts the progression of diabetes-induced experimental nephropathy. Eur. J. Pharmacol. 2010, 636, 137-44, https://doi.org/10.1016/j.ejphar.2010.03.002. 